\title{
PENGAMATAN BIOAKUSTIK PERGERAKAN IKAN SIDAT Anguilla sp. DALAM KONDISI TERKONTROL (AKUARIUM)
}

\section{THE BIOACOUSTIC OBSERVATION OF Anguilla sp. MOVEMENT UNDER CONTROLLED CONDITION (AQUARIUM)}

\author{
Sri Pujiyati ${ }^{1 *}$, Bambang Retnoaji ${ }^{2}$, Ariel Hananya ${ }^{2}$, dan M. Zainuddin Lubis ${ }^{3}$ \\ ${ }^{1}$ Departemen Ilmu dan Teknologi Kelautan, FPIK-IPB, Bogor; *E-mail: sripu@apps.ipb.ac.id \\ ${ }^{2}$ Fakultas Biologi, Universitas Gadjah Mada Yogyakarta \\ ${ }^{3}$ Program Studi Tehnik Geomatika,Politeknik Batam
}

\begin{abstract}
The movement of eels produces a sound called a hydrodynamic sound which is the sound or vibration that results from a change in the medium due to the movement of fish. Hydrodynamic sound intensity occurs when the direction and speed of fish swimming change rapidly. The deflection of the head position will cause a strong displacement of the medium. The displacement causes changes in pressure waves on the medium, which can be detected as sound by the hydrophone. This research aims to analyze the differences in the sound of elver phase eel fish and yellow phase in controlled conditions. The research was conducted at the Laboratory of histology and embryology of the Faculty of Biology, Gadjah Mada University. The research time is August 4-7, 2016. The tools used in this research are: Aquarium glass, headphones, hydrophone, Seaphone, alkaline battery box, laptop. The ingredients used were 5 yellow phase eel and elver phase respectively. Data processing is carried out with the help of the wavelab program 6 and analyzed using the Duncan Multiple Range test (DMRT). The results showed that the elver and yellow phase ell activities are very diverse in terms of the duration of eel's sound during morning, afternoon and night. Sound frequencies patterns recorded from $0-22.03$ $\mathrm{KHz}$. The sound frequency of ell is dominant from $151-450 \mathrm{~Hz}$ of range, and has different sound patern during morning, afternoon and night. The conclusion is that the duration and hydrodynamic sound patterns of elver phase eel and yellow phase were significantly different between morning afternoon, also afternoon - evening, but for the morning - the evening is not significantly different.
\end{abstract}

Keywords: bioacoustic, eel fish, duration and sound pattern

\begin{abstract}
ABSTRAK
Pergerakan Ikan sidat menghasilkan suara yang disebut suara hidrodinamik yang merupakan suara atau getaran yang dihasilkan dari sebuah perubahan di medium karena pergerakan ikan. Intensitas suara hidrodinamik terjadi saat arah dan kecepatan renang ikan berubah secara cepat. Pembelokan posisi kepala akan menyebabkan perpindahan medium yang kuat. Perpindahan tersebut menyebabkan perubahan gelombang tekanan pada medium, yang dapat terdeteksi sebagai suara oleh hydrophone. Penelitian ini bertujuan untuk menganalisis perbedaan suara ikan sidat fase elver dan fase yellow dalam kondisi terkontrol. Penelitian dilakukan di Laboratorium histologi dan embriologi Fakultas Biologi, Universitas Gadjah Mada. Waktu penelitiannya adalah 4-7 Agustus 2016. Alat yang digunakan dalam penelitian ini adalah aquarium kaca, headphone, hidrophone, Seaphone, baterai alkaline kotak, laptop. Bahan yang digunakan masing-masing 5 ekor sidat fase yellow dan fase elver. Hasil penelitian menunjukkan bahwa Aktifitas ikan sidat fase elver dan fase yellow sangat beragam ditinjau dari durasi suara ikan sidat saat pagi,siang dan malam. Pola suara yang terekam berkisar dari frekuensi dari 0 sampai $22.03 \mathrm{KHz}$. Frekuensi suara ikan sidat dominan dikisaran $151-450 \mathrm{~Hz}$, dan memiliki pola suara yang berbeda-beda untuk pagi, siang dan sore. Kesimpulan menunjukkan bahwa durasi dan pola suara hidrodinamika ikan sidat fase elver maupun fase yellow berbeda nyata antara pagi - siang, juga siang - sore, namun untuk pagi - sore tidak berbeda nyata.
\end{abstract}

Kata kunci: bioakustik, ikan sidat, durasi dan pola suara 


\section{PENDAHULUAN}

Biota air pada umumnya mengeluarkan suara. Suara yang dihasilkan biasanya berasal dari organ tertentu. Suara biota ini umumnya digunakan untuk berkomunikasi, mencari pasangan, mengidentifikasi lingkungan. Suara juga dihasilkan dari dampak tingkahlaku seperti kegiatan saat makan, bergerak, menghindari musuh, dan reproduksi (seksualitas dan fase pembesaran). Bio-akustik merupakan ilmu yang mempelajari suara-suara yang dihasilkan oleh makhluk hidup. Penelitian tentang bioakustik terhadap mamalia laut telah dilakukan oleh Croll et al. (2002), Lubis et al. (2016), Macaulay et al. (2017), Laplanche (2007), Tervo et al. (2011), Zimmer (2013).

Anguilla sp. atau yang biasa disebut dengan ikan sidat merupakan ikan katadromus yang umumnya dapat ditemukan di daerah hilir sungai berlumpur yang berbatasan dengan perairan laut yang cukup dalam. Karakter sidat yang merupakan ikan nokturnal seringkali mengakibatkan cukup sulitnya pengamatan yang dilakukan secara in-situ. Penelitian tentang sidat sudah banyak dilakukan antara lain Chrisnal (2010), Gill et al. (2012), Gómez (2007), Hakim et al. (2015).

Pergerakan Ikan sidat menghasilkan suara yang disebut suara hidrodinamik yang merupakan suara atau getaran yang dihasilkan dari sebuah perubahan di medium karena pergerakan ikan. Intensitas suara hidrodinamik terjadi saat arah dan kecepatan renang ikan yang berubah secara cepat. Pembelokan posisi kepala akan menyebabkan perpindahan medium yang kuat. Perpindahan tersebut menyebabkan perubahan gelombang tekanan pada medium, yang dapat terdeteksi sebagai suara oleh hydrophone. Penggunaan hydrophone dalam penelitian sudah banyak dilakukan salah satunya Skarsoulis dan Dosso (2015), Laplanche (2007).

Penelitian ini bertujuan untuk menganalisis perbedaan suara ikan sidat fase elver dan fase yellow dalam kondisi terkontrol.

\section{METODE PENELITIAN}

\subsection{Waktu dan Tempat Penelitian}

Penelitian dilakukan di Laboratorium histologi dan embriologi Fakultas Biologi, Universitas Gadjah Mada, pada tanggal 4-7 Agustus 2016. Analisa data dilakukan di Laboratorium Akustik dan Instrumentasi Kelautan, Departemen Ilmu dan Teknologi Kelautan, Fakultas Perikanan dan Ilmu Kelautan, Institut Pertanian Bogor.

\subsection{Alat dan Bahan}

Alat yang digunakan dalam penelitian ini adalah aquarium kaca, headphone, hidrophone, Seaphone, baterai alkaline kotak, laptop. Bahan yang digunakan 5 ekor sidat fase yellow dengan panjang total (TL): 51,40; 58,$40 ; 60,30 ; 61,70 ; 62,10 \mathrm{~cm}$ dan 5 ekor sidat fase elver dengan panjang total (TL): 9,$30 ; 9,40 ; 9,50 ; 9,70 ; 9,80 \mathrm{~cm}$.

\subsection{Pengambilan Data}

Adapun cara kerja yang dilakukan adalah sebagai berikut : (1) Ikan sidat hasil penangkapan di perairan Kulon Progo, disiapkan masing masing 5 ekor untuk fase elver dan fase yellow di dalam aquarium dengan air yang diganti setiap 3 hari sekali dan diberi makan pelet ikan (2) Peralatan Hidrofon dinyalakan dengan menyambungkan hidrophone ke Sea phone dan memasukan baterai ke dalam seaphone. Seaphone disambungkan ke laptop dan hidrofon di masukan dalam akuarium (3) Pengambilan data dilakukan dengan melakukan perekaman suara pada saat pagi, siang dan malam masing-masing selama 10 menit (4) Hasil rekaman di simpan dalam bentuk data dengan extention .wav.

\subsection{Analisis Data}

Data rekaman suara ikan akan dicuplik pada bagian suara yang diinginkan yang dapat didengar dengan jelas, sebagai 
suara yang berasal dari gerak ikan sidat dengan bantuan program wavelab 6 . Hasil pencuplikan diperoleh 252 data suara ikan, kemudian data diolah dengan menggunakan 3D Frekuensi Analysis untuk melihat frekuensi dan waktu. Spectrum Analyzer digunakan untuk melihat sinyal dalam bentuk Fast Fourier Transform (FFT). Selanjutnya pola suara dalam bentuk FFT akan diexstrak dalam bentuk *.txt. Analisis pola suara di mulai dari awal puncak hingga berakhirnya puncak (berkisar frekuensi $151-452 \mathrm{~Hz}$ ).

Langkah selanjutnya, data yang telah diextrak akan digabungkan dan dirata-rata berdasarkan waktu dari setiap fase ikan sidat. Analisa statistik dengan Uji Duncan Multiple Range test untuk mengetahui perbedaan durasi suara ikan sidat pada fase elver maupun yellow juga perbedaan pola suara ke dua fase ikan sidat.

\section{HASIL DAN PEMBAHASAN}

Ikan sidat Anguilla sp memiliki siklus yang berbeda dengan ikan-ikan pada umumnya. Ikan sidat bertelur di perairan laut dalam dan dewasa banyak ditemukan di sungai-sungai (Chrisnal, 2010). Ikan sidat yang mencapai larva ikan sidat (fase elver) akan beruaya dari perairan laut ke perairan tawar melalui muara sungai. Ruaya anadromus elver tersebut berhubungan dengan musim. Diperkirakan ruaya elver dimulai pada awal musim hujan namun faktor arus sungai dan keadaan bulan sangat mempengaruhi energi ruayanya. Gill et al. (2012) menduga bahwa migrasi ikan sidat di Inggris ikut dipengaruhi oleh pembangunan dan operasi pengembangan energi terbarukan laut.

Fase hidup ikan sidat yang cukup unik tersebut telah menarik para peneliti untuk melakukan penelitian. Salah satunya Antunes dan Tesch (2006) telah melakukan penelitian tentang fase elver dan glass ell.

Penyebaran ikan sidat sangat luas, di Indonesia sendiri ikan sidat banyak ditemukan di berbagai wilayah perairan
Indonesia. Gambar 1 menunjukkan sebaran ikan sidat.

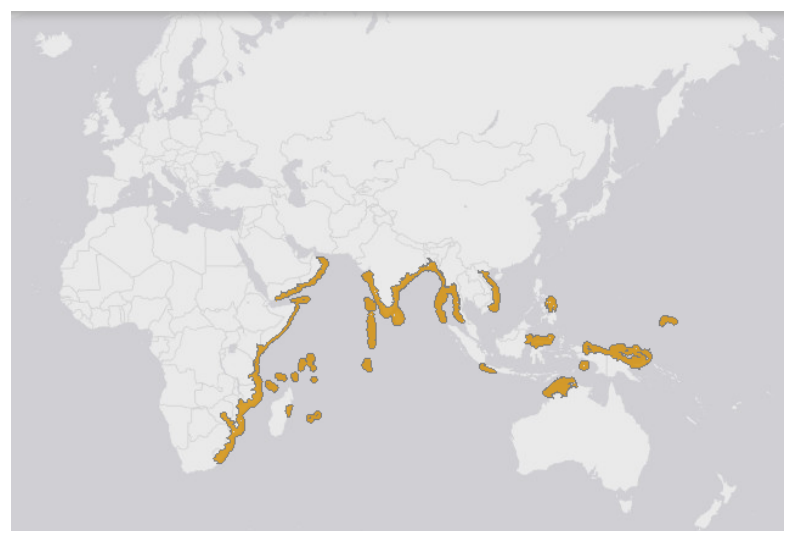

Gambar 1. Penyebaran Ikan Sidat (Jacoby et al., 2014).

Ikan sidat memiliki bentuk tubuh memanjang seperti ular, dalam berenang ikan sidat meliuk-liukkan tubuhnya. Diponegoro (2007) menyatakan gerakan ikan yang dibangkitkan oleh gerakan meliuk badan ikan secara horizontal disebut amplitude horizontal wriggle. Pergerakan ikan sidat ini menghasilkan suara yang disebut suara hidrodinamik yang merupakan suara atau getaran yang dihasilkan dari sebuah perubahan di medium karena pergerakan ikan sidat. Pitcher (1993) menyatakan jenis suara yang dihasilkan dengan menggerakkan tubuhnya disebut suara stridulatory

Hasil perekaman suara sidat berjumlah 252 data suara yang berasal dari sidat fase elver dan sidat fase yellow. Data yang ada setelah dianalisa dengan software wavelab 6, diperoleh informasi suara ikan sidat terlama mencapai 217 detik dan suara terpendek 8 detik. Rata-rata waktu satu suara adalah 31.64 detik, namun suara yang banyak ditemukan selama 12 detik. Hal ini memberikan gambaran bahwa ikan bergerak dalam jangka waktu yang relative pendek, dan dimungkinkan ikan beristirahat karena menemukan lubang persembunyian (paralon) atau berhenti untuk makan.

Aktifitas ikan pagi, siang dan sore sangat beragam bila ditinjau dari durasi suara 
ikan sidat. Fase elver memiliki durasi ratarata terpanjang di siang hari diikuti pagi dan sore. Fase yellow sore hari memiliki durasi suara lebih panjang diikuti pagi dan siang. Bila dibandingkan antara fase elver dan fase yellow maka terlihat durasi suara sidat fase yellow lebih lama dibandingkan dengan fase elver kecuali saat siang hari (Gambar 2). Hal ini menunjukkan ikan sidat fase elver lebih aktif pada siang hari, namun saat pagi dan sore ikan fase yellow lebif aktif. Hal ini berbeda dengan kondisi di alam dimana ikan sidat aktif pada malam hari. Ini terjadi karena ikan sidat sudah mengalami penyesuaian dengan kondisi di ruangan sehingga mengubah prilaku dirinya. Fahmi (2010) menyatakan bahwa perubahan lingkungan turut mempengaruhi perubahan tingkah laku ikan sidat.

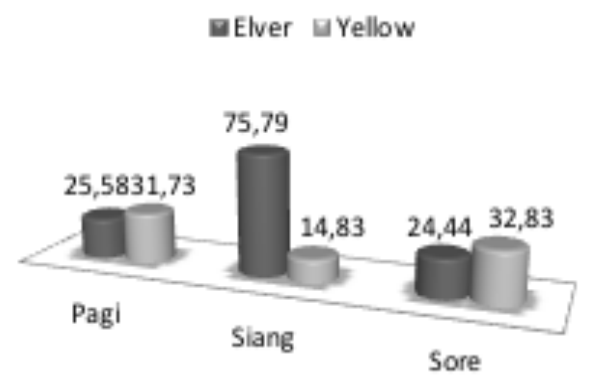

Gambar 2. Durasi suara ikan sidat berdasarkan waktu perekaman.

Berdasarkan uji Duncan Multiple Range test (Tabel 1) untuk ikan sidat fase elver menunjukkan bahwa durasi suara ikan saat pagi hari tidak berbeda nyata dengan durasi suara ikan di sore hari, namun untuk durasi suara ikan siang hari berbeda nyata dengan durasi suara ikan sidat saat pagi maupun sore hari. Hal ini tidak berbeda dengan durasi suara ikan fase yellow, pada perekaman suara pagi hari tidak berbeda nyata dengan suara ikan sidat sore hari, namun berbeda nyata dengan perekaman sidat pada siang hari.
Tabel 1. Durasi suara ikan fase elver maupun fase yellow pada pagi, siang dan sore.

\begin{tabular}{lc}
\hline \multicolumn{1}{c}{ Sampel } & Durasi (dtk) \\
\hline Elver Pagi & $25,58 \pm 27,82^{\mathrm{a}}$ \\
Elver Siang & $75,79 \pm 49,41^{\mathrm{b}}$ \\
Elver sore & $24,44 \pm 29,09^{\mathrm{a}}$ \\
Yellow Pagi & $31,73 \pm 32,32^{\mathrm{c}}$ \\
Yellow Siang & $14,82 \pm 3,23^{\mathrm{d}}$ \\
Yellow sore & $32,83 \pm 33,12^{\mathrm{c}}$ \\
\hline
\end{tabular}

Keterangan : Huruf yang berada dibelakang angka yang sama menunjukan tidak adanya beda nyanta pada uji DMRT dengan tingkat kepercayaan $95 \%$.

Pola suara yang terekam berkisar dari frekuensi dari 0 sampai $22.03 \mathrm{KHz}$. Frekuensi suara ikan sidat dominan dikisaran 151 - $450 \mathrm{~Hz}$ (Gambar 3). Hasil penelitian Wirawanto (2002) frekuensi maksimal untuk suara ikan kerapu saat makan berkisar 1400$1700 \mathrm{~Hz}$. Hal ini menunjukkan suara ikan sidat yang dihasilkan oleh gerakan ikan sidat sangat rendah frekuensinya dibandingkan frekuensi ikan kerapu saat makan. Hal ini terjadi karena gerakan ikan sidat memiliki jumlah getaran lebih sedikit dibandingkan getaran ikan kerapu saat makan. Sedikitnya getaran saat ikan sidat bergerak dikarenakan ikan sidat memiliki lendir di seluruh tubuhnya. Lendir ini akan mengurangi gesekan badan dengan air. Widyasari (2013) menyatakan tubuh ikan sidat diselimuti oleh lendir yang cukup banyak untuk melindungi dirinya.

Berdasarkan Gambar 3 terlihat pola suara ikan fase elver maupun fase yellow berfluktuasi di saat pagi, siang dan sore. Berdasarkan hasil analisis uji Duncan Multiple Range test (Tabel 2). Pola suara ikan fase elver maupun fase yellow antara pagi dan sore tidak berbeda nyata. Namun untuk siang hari berbeda nyata baik dengan pagi maupun siang. 


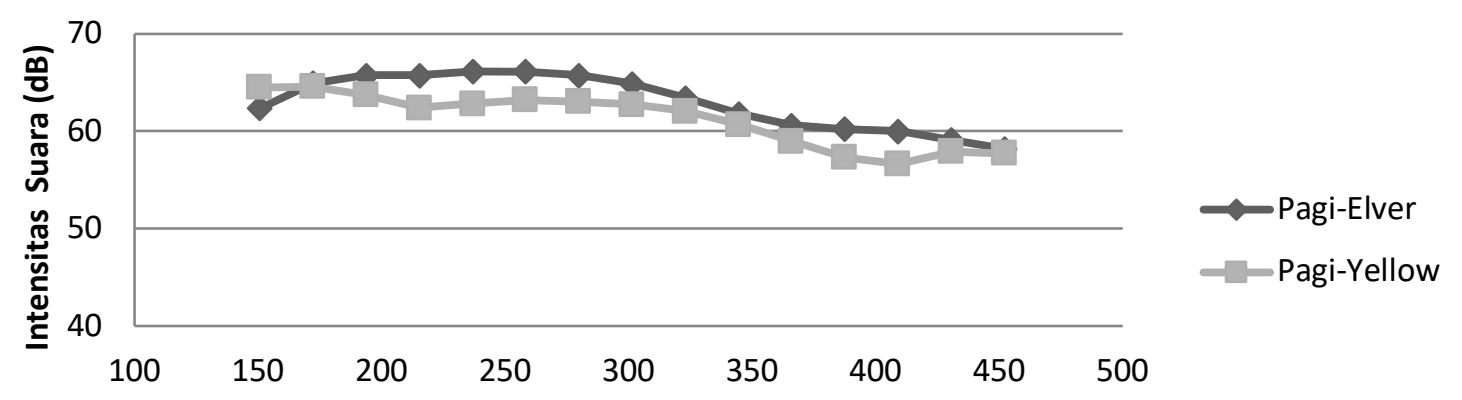

Frekuensi (Hz)

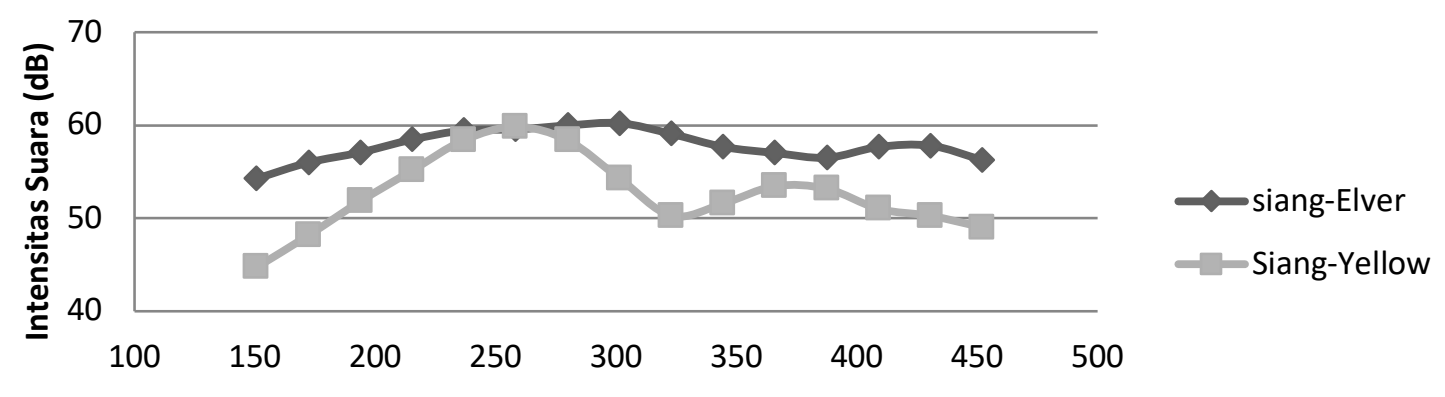

Frekuensi (Hz)

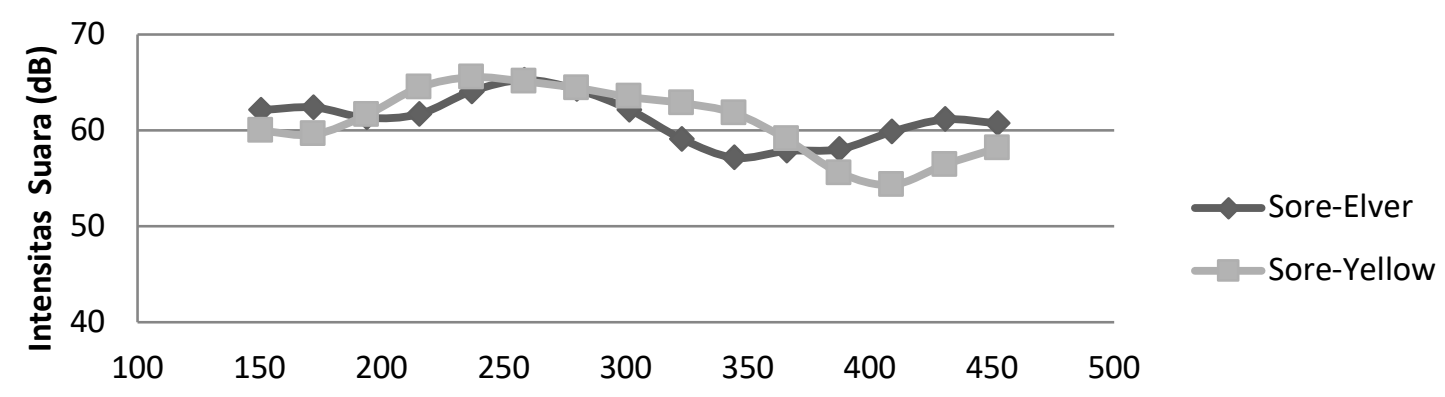

Frekuensi (Hz)

Gambar 3. Pola suara ikan sidat saat pagi, siang dan sore.

Tabel 2. Perbandingan pola suara ikan fase elver maupun fase yellow saat pagi, siang dan sore.

\begin{tabular}{lccc}
\hline \multirow{2}{*}{ Jenis } & \multicolumn{3}{c}{ Waktu } \\
\cline { 2 - 4 } & Pagi & Siang & Sore \\
\hline Elver & $59,33761 \pm 3,842483^{\mathrm{b}}$ & $53,03282 \pm 5,17492^{\mathrm{a}}$ & $58,52931 \pm 4,835413^{\mathrm{b}}$ \\
Yellow & $57,26032 \pm 5,426849^{\mathrm{d}}$ & $50,51136 \pm 5,308123^{\mathrm{c}}$ & $56,98226 \pm 6,518271^{\mathrm{d}}$ \\
\hline
\end{tabular}

Keterangan : Huruf yang berada dibelakang angka yang sama menunjukkan tidak adanya perbedaan nyata pada uji DMRT dengan tingkat kepercayaan $95 \%$.

\section{KESIMPULAN}

Suara hidrodinamik ikan sidat fase elver dan fase yellow memiliki durasi dan pola suara saat pagi hari tidak berbeda nyata dengan durasi dan pola suara ikan sidat di sore hari, namun untuk durasi dan pola suara ikan siang hari berbeda nyata dengan durasi dan pola suara ikan sidat saat pagi maupun sore hari. 


\section{DAFTAR PUSTAKA}

Antunes, C. and F.W. Tesch. 2006. A critical consideration of the metamorphosis zone when identifying daily rings in otoliths of European eel, Anguilla anguilla (L.). Ecology of Freshwater Fish, 6(2):102-107.

Chisnal, B.L. 1989. Age, growth, and condition of freshwater eels (Anguilla sp.) in backwaters of the lower Waikato River, New Zealand. New Zealand $J$. of Marine and freshwater Research, 23(4):459-465. Doi.org/10.1080/00288330.1989.951 6382.

Croll,D.A., C.W. Clark, A. Acevedo, B. Tershy, S. Flores, J. Gedamke, and J. Urban. 2002. Bioacoustics: Only male fin whales sing loud songs. Nature, 417:809-811. DOI:10.1038/4 17809a.

Diponegoro, A.D. 2007. Analisis Penentuan jenis kawanan ikan berdasarkan deteksi fasa pentulan gelombang akustik dan penerapan hidden markov model. Institut Pertanian Bogor. Bogor $245 \mathrm{hlm}$.

Fahmi, M.R. 2010. Phenotypic platisity kunci sukses adaptasi ikan migrasi: studi kasus Ikan Sidat (Anguilla Sp.). Prosiding forum inovasi teknologi akuakultur. pusat penelitian dan pengembangan perikanan. Badan Penelitian dan pengembangan Kelautan dan Perikanan.Hlm.:9-17.

Gill, A.B., M. Bartlett, and F. Thomsen. 2012. Potential interactions between diadromous fishes of U.K. conservation importance and the electromagnetic fields and subsea noise from marine renewable energy developments. J.of Biology, 81(5): 1791-1795. doi.org/10.1111/j.10958649.2012.03374.x.

Gómez, M. and A. Salvador. 2007. AnguilaAnguilla anguilla (Linnaeus, 1758) En: Enciclopedia virtual de los vertebrados españoles. Salvador, A., Elvira, B. (Eds.). Museo Nacional de Ciencias Naturales. Madrid. $14 \mathrm{p}$.

Hakim, A.A., M.M. Kamal, N.A. Butet, R. Affandi. 2015. Komposisi spesies Ikan Sidat (Anguilla spp.) di delapan sungai yang bermuara ke Teluk Palabuhanratu, Sukabumi, Indonesia. J. Ilmu Dan Teknologi Kelautan Tropis, 7(2):573-586. http://dx.doi. org/10.29244/jitkt.v7i2.11027.g8920.

Jacoby D., I.J. Harrison, and M. Gollock. 2014. Anguilla bicolor. The IUCN Red List of Threatened Species 2014:e.T166894A67015710. http:// dx.doi.org/10.2305/IUNC.UK.20141.RLTS.T166894A67015710.en.

Laplanche. 2007. A bayesian method to estimate the depth and the range of phonating sperm whales using a single hydrophone. J. Acoust. Soc. Am, (3):1519-1528. DOI:10.1121/1. 2436644.

.Lubis, M.Z., S. Pujiyati, and T. Hestirianoto. 2016. Bioacoustic spectral whistle sound and behaviour of male dolphin bottle nose (Tursiops aduncus) At Safari Park Indonesia, Cisarua Bogor. Waste Technology and International J., 4(1):24-30.

Macaulay, J., J. Gordon, D. Gillespie, C. Malinka, and C. Northridge. 2015. Passive acoustic methods for finescale tracking of harbor porpoises in tidal rapids. J. Acoust. Soc. Am., 141: 1120-1132. DOI: 10.1121/1.4976077.

Pitcher, T.J. 1993. Behaviour of teleost fishes $2^{\text {nd }}$ ed. Clays Ltd, StIves plc. London (UK). 740 p.

Skarsoulis, E.K. and S.E. Dosso. 2015. Linearized two-hydrophone localization of a pulsed acoustic source in the presence of refraction: Theory and simulations. J. Acoust. Soc. Am., 138:2221-2234. DOI:10.1121/1.4930 937.

Tervo, O.M. M.F. Christoffersen, S.E. Parks, R.M. Kristensen, and P.T. Madsen. 
2011. Evidence for simultaneous sound production in the bowhead whale (Balaena mysticetus). $J$. Acoust. Soc. Am., 130(4):2257-2262. DOI: $10.1121 / 1.3628327$.

Wirawanto, S. 2002. Studibioakustik suara stridulatory pada tingkah laku makan (Feeding Behavior) IkanKerapuTikus (cromileptesaltivelis). Fakultas Perikanan. Institut Pertanian Bogor. Bogor. $54 \mathrm{hlm}$.

Widyasari, R.A.H. 2013. Disain terpadu pengembangan industri perikanan sidat Indonesia (Anguilla spp.) berkelanjutan di Palabuhanratu
Kabupaten Sukabumi Provinsi Jawa Barat. Institut Pertanian Bogor. Bogor. 217 hlm.

Zimmer, W.M.X. 2013. Range estimation of cetaceans with compact volumetric arrays. J. Acoust. Soc. Am., 134(3): 2610-2618. http://dx.doi.org/10.1121/ 1.4817892 .

$\begin{array}{ll}\text { Diterima } & : 11 \text { Mei } 2018 \\ \text { Direview } & : 15 \text { Mei } 2018 \\ \text { Disetujui } & : \text { 05 Juli } 2018\end{array}$

Diterima : 11 Mei 2018

Disetujui : 05 Juli 2018 
